\title{
Mandibular resorption and vocal cord paralysis: a catastrophic form of systemic sclerosis
}

\author{
Pedro Mendonça, ${ }_{1}^{1,2}$ Anna Viola Taulaigo, ${ }^{\circ}$ Antonio Caetano, ${ }^{3}$ \\ Maria Francisca Moraes-Fontes ${ }^{1}$
}

'Unidade de Doenças Autoimunes/Medicina 7.2, Hospital de Curry Cabral, Centro Hospitalar de Lisboa Central, Lisboa, Portugal

${ }^{2}$ Serviço de Medicina, Hospital de Faro, Centro Hospitalar Universitário do Algarve, Faro, Portugal

${ }^{3}$ Serviço de Radiologia, Hospital de Curry Cabral, Centro Hospitalar de Lisboa Central, Lisboa, Portugal

\section{Correspondence to} Dr Anna Viola Taulaigo, annataulaigo@gmail.com

PM and AVT contributed equally.

Accepted 7 February 2019

\section{Check for updates}

(c) BMJ Publishing Group Limited 2019. No commercial re-use. See rights and permissions. Published by BMJ.

To cite: Mendonça $\mathrm{P}$, Taulaigo AV, Caetano A, et al. BMJ Case Rep

2019:12:e228262

doi:10.1136/bcr-2018-

228262

\section{SUMMARY}

Sudden respiratory distress in association with severe weight loss are unusual features of systemic sclerosis (SSc). We report the case of a 56-year-old Caucasian woman with a 9-year history of a diffuse form of SSC who presented with acute stridor due to vocal cord paralysis and required an emergency tracheostomy. She had sought medical attention only after 4 years of disease onset, presenting with a mask-like face, diffuse skin thickening, acro-osteolysis and severe interstitial lung disease. Even though skin tightness improved after immunosuppressive treatment, several spontaneous facial fractures and episodes of dysphagia and choking occurred in the years that followed. At the time of stridor, she was severely malnourished and a percutaneous endoscopic gastrostomy was required for feeding. Permanent vocal cord damage in combination with severe loco-regional bone resorption resulted in severe disability and impaired nutrition. We hereby highlight the features of SSc for which therapy remains challenging.

\section{BACKGROUND}

Mandibular resorption and vocal cord paralysis are recognised features of systemic sclerosis (SSc), both likely to be driven by vasculopathy and peripheral ischaemia. ${ }^{12}$ Facial skin thickening and muscular atrophy contribute to bone resorption. ${ }^{3}$ In turn, laryngeal inflammation has been attributed to gastro-oesophageal reflux, vocal fold thickening, nodularity or fibrosis, ${ }^{45}$ while vocal cord paralysis has been related to cricoarytenoid ankyloses and nerve injury. ${ }^{67}$ According to literature, mandibular resorption in SSc has a variable prevalence raising from $6.6 \%$ to $46.7 \%,{ }^{3}$ and it correlates with longer disease duration. Most evidence comes from case reports and small case series, in which mandibular resorption is not related to a specific serological pattern. It may involve temporomandibular joint and clinical manifestations vary from any symptoms to severe pain and mouth opening limitation. Due to its consequences, early detection is crucial and active pursuing of mandibular involvement in SSc patients has been recommended. ${ }^{8}$

Vocal cord paralysis seems to be extremely rare in SSc and few cases were reported ${ }^{6}$; thus estimation of real prevalence and clinical and serological correlates is challenging. Coexistence of these two rare and severe complications in an individual patient has not been previously described. This report highlights a unique combination of almost untreatable SSc orofacial manifestations with high morbidity and impact on patient's quality of life.

\section{CASE PRESENTATION}

In April 2017, a 56-year-old woman with a 9-year history of a diffuse form of SSc presented with acute stridor. Laryngoscopy showed macroscopically normal vocal cords in a nearly adducted position and an emergency tracheostomy was performed. Disease onset had been characterised by generalised skin thickening at age 47 but the patient had sought medical attention only at age 51 . She had a masklike face, microstomia, limited and painful jaw movements, salt and pepper skin, acro-osteolysis, a chronic cough and recent onset effort dyspnoea. She was unable to lift her arms and had difficulty with self-care and daily activities. The modified Rodnan skin score (mRSS) was 42 and the left wrist was inflamed and immobile. Complete blood count and biochemistry profile were normal. Further tests revealed a high erythrocyte sedimentation rate (ESR) $(72 \mathrm{~mm} /$ hour$)$; the antinuclear antibody test was positive with a nucleolar pattern and a titre of 1/640; the immunoblot (Euroimmun@) revealed a $3+$ positivity for anti-topoisomerase I antibody. Other features included a late scleroderma capillaroscopy pattern, a large calcific deposit in the left wrist, extensive non-specific interstitial pneumonia (NSIP), a restrictive pattern in the respiratory function tests (Tiffeneau index of 86\%; forced vital capacity of $1.97 \mathrm{~L}$ units [ $75 \%$ of predicted]; carbon monoxide diffusing capacity adjusted for alveolar volume (DLCO/VA) of $0.6 \mathrm{mmol} / \mathrm{min} / \mathrm{kPa} / \mathrm{L}[35 \%$ of predicted]) and diffuse oesophageal dilatation. Echocardiography was suggestive of pulmonary arterial hypertension but this was not confirmed on right heart catheterisation. The patient declined to take a daily dose of prednisolone. She was initially treated with a proton pump inhibitor (PPI), daily bosentan and monthly intravenous cyclophosphamide $\left(750 \mathrm{mg} / \mathrm{m}^{2}\right)$ for 6 months, after which she started mycophenolate mofetil (MMF) $1.5 \mathrm{~g} /$ day. Improvement was documented with an mRSS decrease to 20 and lung function stabilisation.

At age 53, the patient reported episodes of choking and swallowing difficulties. There was neither dysphonia nor hoarseness. In the following months, spontaneous fractures of the left mandibular ramus and symphysis occurred. No bisphosphonates had ever been prescribed and bone densitometry was normal. In January 2017, she still 


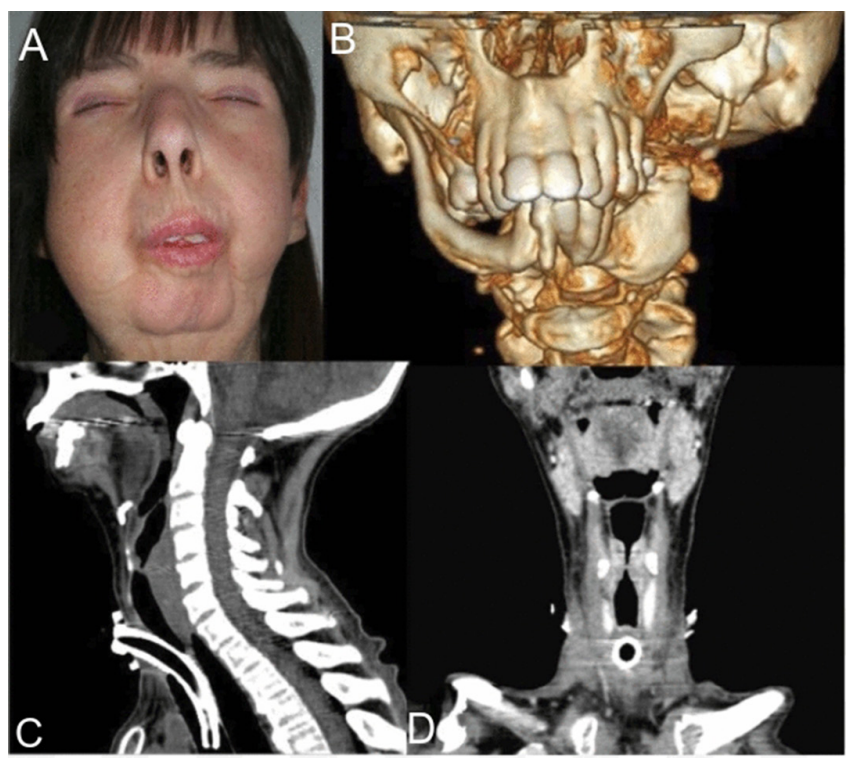

Figure 1 (A) Facial asymmetry and retrognathia; (B) marked facial bone resorption as evidenced by the $3 \mathrm{D}$ reconstruction of facial $\mathrm{CT}$; $(\mathrm{C})$ vocal cord paralysis in non-contrast CT sagittal and (D) coronal views.

was on MMF (1.5 g/day), but experienced worsening of peripheral arthritis and respiratory function tests. For this reason, a switch to subcutaneous tocilizumab (162 mg/week) was made. Tocilizumab is a monoclonal anti-interleukin 6 (IL-6) receptor- $\alpha$ antibody and, even if it is still used as an off-label therapy, it seems promising in controlling cutaneous, pulmonary and even articular involvement ${ }^{9}{ }^{10}$ due to the important role that IL-6 plays in SSc pathogenesis. ${ }^{11}$ In our specific situation, tocilizumab was chosen considering refractory disease on MMF, aiming to stabilise respiratory function and articular disease. The patient had temporary relief from her joints complaints. There was severe, non-quantified weight loss in 3 months prior to hospital admission.

\section{INVESTIGATIONS}

Facial asymmetry (figure 1A) and retrognathia were associated with loss of the mandibular ramus and condyle (figure 1B), as showed in CT scan performed with bone 3D reconstruction. The hyoid bone remained intact. In addition, CT imaging of the neck and thorax failed to reveal any infiltrative lesions or potential compressive structures in the laryngeal nerve tracts. Mediastinal, peri-tracheal and aorto-pulmonary lymph nodes were unremarkable. The retrognathia caused marked distortion of the pharyngeal anatomy, pushing the epiglottis against the posterior pharyngeal wall, partially obstructing the opening of the Eustachian tubes and there was hypoesthesia of the upper larynx. The vocal cords were fixed in adduction (figure 1C,D), a finding that was confirmed after 6 months on repeated laryngoscopy. Laryngeal electromyography is not available in our hospital centre.

\section{DIFFERENTIAL DIAGNOSIS}

Unintentional weight loss might arise from innumerous medical conditions and differential diagnosis is wide. In SSc patients, specific issues should be addressed. First of all, facial skin involvement and bone resorption may heavily disrupt orofacial anatomy, with consequences in mouth opening and chewing capacity. Teeth can be affected and meticulous oral care is recommended. Xerostomia is common and may interfere with removable dentures use. Moreover, SSc patients may present with dysphagia, either due to oropharyngeal muscle involvement or due to gastro-oesophageal reflux disease (GERD) and oesophageal dismotility, limiting oral intake. Small intestine involvement might lead to small intestine bacterial overgrowth (SIBO) syndrome that in turn is a cause of malnutrition and weight loss.

In the case we presented, malnutrition and weight loss may be multifactorial. Nevertheless, we claim that evolving mandibular resorption and vocal cord paralysis play a major role. The patient had known oesophageal involvement as previously reported and she was already on PPI and prokinetic drugs, but endoscopy performed in April 2017 showed diminished oesophageal peristalsis, already known, and did not show worsening of GERD, gastritis, ulcers or any lesion de novo. She refused barium swallow study and more accurate functional motility studies were unavailable in our centre. Also, she did not experience any other symptoms like bloating, abdominal distension, nausea, vomiting, diarrhoea or steatorrhoea nor vitamin deficiencies, making SIBO syndrome less probable. A therapeutic challenge with antibiotics was made indeed without clinical improvement.

\section{TREATMENT}

When mandibular reabsorption occurred, corrective surgery was unfeasible and an oral splint was not tolerated. She was given dietary advice-calcium and vitamin D supplements. At the time of stridor, she weighed $38 \mathrm{~kg}$ (body mass index of 14.8) and, due to malnutrition and high aspiration risk, percutaneous endoscopic gastrostomy (PEG) was required for feeding. Tracheostomy was maintained due to irreversibility of vocal cord paralysis.

\section{OUTCOME AND FOLLOW-UP}

Over the following 18 months, the patient regained and stabilised her weight ( $8 \mathrm{~kg}$ since PEG was introduced), showing that orofacial manifestations of SSc and consequent reduced oral intake might have been mainly responsible for weight loss. She did not develop any clinical manifestation suggesting another underlying disease, namely neoplastic, contributing to weight loss. Unfortunately, she suffered from repeated PEG site and respiratory tract infections, as a result of which tocilizumab was withdrawn. There has been progressive deterioration in lung fibrosis with frequent coughing spells. Over the past 6 months, she has taken prednisolone $10 \mathrm{mg} /$ day with symptomatic relief. The patient has a supportive husband and son and has so far refused any form of psychological or psychiatric support. She is closely co-followed by the Interstitial Lung Disease and Ear, Nose and Throat Units.

\section{DISCUSSION}

The patient displayed severe and disabling manifestations of SSc, namely a mask-like face, microstomia, severe skin thickening, calcinosis, acro-osteolysis, digital ulcers, interstitial lung disease and oesophageal dilatation. Even though this was a late presentation of disease, the initial therapeutic approach reduced skin thickness, halted lung inflammation and slightly improved her functional status. Of note, she did not receive steroids and there was no generalised osteoporosis. When the mandibular fractures occurred, no therapeutic option was deemed effective for the loco-regional bone resorption, which evolved inexorably with total condylolysis and non-union of the mandible. Even though surgical reconstruction of temporomandibular joint has been successfully performed, ${ }^{12}$ the patient was considered unfit for any intervention. Frequent choking episodes, likely at the origin of weight loss, could have contributed to vocal cord dysfunction. Instead, we hypothesise that compressive or ischaemic laryngeal 
nerve damage is the most likely cause for permanent vocal cord paralysis on the basis of anatomical distortion and decreased sensation and in the absence of cricoarytenoid or vocal cord abnormalities. This report highlights severe orofacial features of SSc for which there are no current management guidelines.

\section{Learning points}

- Combined mandibular resorption and vocal cord paralysis may occur as a late feature of systemic sclerosis (SSc).

- Orofacial manifestations of SSc might be severe and affect patients' quality of life.

- Therapeutic options of mandibular resorption remain unsatisfactory and patients' care is a challenge.

Contributors AVT, PM and MFM-F conceived the work. AVT, PM and AC collected the data and $A C$ especially contributed to images selection and interpretation. AVT and PM drafted the article. All the authors critically revised the work and gave final approval of the version submitted. AVT and PM contributed equally to this paper.

Funding The authors have not declared a specific grant for this research from any funding agency in the public, commercial or not-for-profit sectors.

Competing interests None declared.

Patient consent for publication Obtained.

Provenance and peer review Not commissioned; externally peer reviewed.

\section{REFERENCES}

1 Gabrielli A, Avvedimento EV, Krieg T. Scleroderma. N Eng/ J Med Overseas Ed 2009;360:1989-2003.

2 Matucci-Cerinic M, Kahaleh B, Wigley FM. Review: evidence that systemic sclerosis is a vascular disease. Arthritis Rheum 2013:65:1953-62.

3 Jung S, Martin T, Schmittbuhl M, et al. The spectrum of orofacial manifestations in systemic sclerosis: a challenging management. Oral Dis 2017:23:424-39.

4 Pepper JP, Kupfer RA, McHugh JB, et al. Histopathologic findings and clinical manifestations in a patient with dysphonia and vocal fold involvement by systemic sclerosis. Arch Otolaryngol Head Neck Surg 2011;137:816-9.

5 Bélénotti P, Lagier A, Granel B, et al. Atrophy of the vocal fold: An usual cause of hoarseness in scleroderma. Joint Bone Spine 2015;82:206

6 Singh RR, Malaviya AN, Kumar A, et al. Vocal cord palsy in a patient with progressive systemic sclerosis. J Rheumatol 1988;15:882-3.

7 Viner DD, Sabri A, Tucker HM. Bilateral cricoarytenoid joint ankylosis in scleroderma. Otolaryngol Head Neck Surg 2001;124:696-7.

8 Matarese G, Isola G, Alibrandi A, et al. Occlusal and MRI characterizations in systemic sclerosis patients: A prospective study from Southern Italian cohort. Joint Bone Spine 2016:83:57-62.

9 Khanna D, Denton CP, Jahreis A, et al. Safety and efficacy of subcutaneous tocilizumab in adults with systemic sclerosis (faSScinate): a phase 2, randomised, controlled trial. Lancet 2016:387:2630-40.

10 Elhai M, Meunier M, Matucci-Cerinic M, et al. Outcomes of patients with systemic sclerosis-associated polyarthritis and myopathy treated with tocilizumab or abatacept: a EUSTAR observational study. Ann Rheum Dis 2013;72:1217-20.

11 Muangchan C, Pope JE. Interleukin 6 in systemic sclerosis and potential implications for targeted therapy. J Rheumatol 2012;39:1120-4.

12 MacIntosh RB, Shivapuja PK, Naqvi R. Scleroderma and the temporomandibular joint: reconstruction in 2 variants. J Oral Maxillofac Surg 2015;73:1199-210.

Copyright 2019 BMJ Publishing Group. All rights reserved. For permission to reuse any of this content visit

https://www.bmj.com/company/products-services/rights-and-licensing/permissions/

BMJ Case Report Fellows may re-use this article for personal use and teaching without any further permission.

Become a Fellow of BMJ Case Reports today and you can:

- Submit as many cases as you like

- Enjoy fast sympathetic peer review and rapid publication of accepted articles

- Access all the published articles

Re-use any of the published material for personal use and teaching without further permission

For information on Institutional Fellowships contact consortiasales@bmjgroup.com

Visit casereports.bmj.com for more articles like this and to become a Fellow 